\title{
Ensino-aprendizagem em ambiente virtual: a experiência dos docentes no Marajó,
}

\section{Brasil}

\author{
Teaching-learning in a virtual environment: the experience of teachers in Marajó, Brazil \\ Enseñanza-aprendizaje en un entorno virtual: la experiencia de los docentes en Marajó, Brasil
}

\section{Resumo}

$\mathrm{O}$ artigo relata experiências adquiridas durante às atividades realizadas em uma formação online com docentes da Educação Básica do município de Breves, no arquipélago do Marajó (Estado do Pará, Brasil). Tal ação extensionista, aconteceu durante o mês de março em 2021. O percurso metodológico ocorreu por meio de dois ambientes virtuais, pela plataforma Google Meet e Google Sala de Aula. Este estudo de caso consistiu em pesquisa bibliográfica e a pesquisa-ação. A formação teve como objetivo refletir, debater e propor práticas pedagógicas inovadoras visando uma educação antirracista no território marajoara. Assim, os(as) participantes tiveram a oportunidade não apenas de compreender conceitos e práticas pedagógicas oportunizados na formação, mas também buscar construir uma cultura educacional mais humana e inclusiva através dos ambientes virtuais de aprendizagem.

Palavras-chave: Virtual; Docentes; Marajó; Relações étnico-raciais.

\begin{abstract}
The article reports experiences acquired during activities carried out in an Online training with teachers of Basic Education in the municipality of Breves, in the Marajó archipelago (State of Pará, Brazil). Such extension action took place during the month of March in 2021. The methodological path took place through two virtual environments, through the Google Meet and Google Classroom platform. This case study consisted of bibliographic research and action research. The training aimed to reflect, debate and propose innovative pedagogical practices aimed at anti-racist education in Marajoara territory. Thus, the participants had the opportunity not only to understand pedagogical concepts and practices offered in training, but also to seek to build a more human and inclusive educational culture through virtual learning environments.
\end{abstract}

Keywords: Virtual; Teachers; Marajo; Ethnic-racial relations.

\section{Resumen}

El artículo relata experiencias adquiridas durante las actividades realizadas en una formación online con profesores de Educación Básica en el municipio de Breves, en el archipiélago de Marajó (Estado de Pará, Brasil). Dicha acción de prórroga tuvo lugar durante el mes de marzo de 2021. El recorrido metodológico se realizó a través de dos entornos 
virtuales, a través de la plataforma Google Meet y Google Classroom. Este estudio de caso consistió en investigación bibliográfica e investigación-acción. La formación tuvo como objetivo reflexionar, debatir y proponer prácticas pedagógicas innovadoras dirigidas a la educación antirracista en el territorio de Marajoara. Así, los participantes tuvieron la oportunidad no solo de comprender conceptos y prácticas pedagógicas ofrecidas en la formación, sino también de buscar construir una cultura educativa más humana e inclusiva a través de entornos virtuales de aprendizaje.

Palabras clave: Virtual; Docentes; Marajó; Relações étnico-raciais.

\section{Introdução}

Este texto, busca compartilhar experiências desenvolvidas durante as atividades realizadas na formação Online, ocorrida durante o mês de março de 2021. O público-alvo foram os docentes da Educação Básica do município de Breves, arquipélago do Marajó (Pará, Brasil). Tal ação faz parte do projeto intitulado "Educando pelos rios marajoaras: ações e estratégias para promoção da equidade racial durante a pandemia (Covid 19)", aprovado no Edital nº 04/2020 do PROEXTENSÃO/IFPA/PROEX, o qual objetivou refletir, debater e propor metodologias para trabalhar a temática racial na Educação Básica.

É importante destacar que o tripé ensino, pesquisa e extensão é fundamental para formação acadêmico-profissional (Silva, 2017), os quais não devem ser dissociados. A extensão é de suma importância para o ensino aprendizagem, visto que possui um um caráter educativo, cultural e científico (Jantke \& Caro, 2013). Além disso, é uma maneira das instituições de ensino proporem projetos e ações de inteveção para amenizar vários problemas existentes na sociedade. Nesse sentido, autores como Portes et al. (2011), Gonçalves et al. (2016) e Silva (2017), tem mostrado a revência da extensão no processo de ensino aprendizagem.

Nessa perspectiva, descreveremos a importância da formação Online, sobretudo, nesse momento de emergência causado pela Pandemia (COVID-19), que obrigou a suspensão das atividades presenciais nas escolas em todos os países e, ao mesmo tempo, observou-se o crescimento do racismo, da injúria racial, das desigualdades sociais e de mortes de pessoas negras no Brasil. Assim, a formação foi um momento de debater sobre conceitos, práticas pedagógicas e de denunciar práticas racistas e outras violências enfrentadas pelo povo negro na sociedade brasileira, e no território marajoara, sobretudo, no espaço escolar, bem como discutiu sobre formas de enfrentamento a esta difícil realidade.

Tendo em vista tal realidade, buscou-se o ambiente virtual como meio para interagir com os participantes da formação, uma vez que a Tecnologia de Informação e Comunicação (TIC) vem sendo inserida no processo de ensino aprendizagem em diferentes países, nesse sentido tem contribuído na divulgação do conhecimento científico. O desenvolvimento das TIC's, sobretudo da internet, tem possibilitado outras formas de se configurar a sala de aula (Harvey, 2001). Tal configuração está relacionada a mudanças de paradigmas, esta foi estimulada devido o grande poder de interação que a internet propiciona (Schlemmer, 2005).

Desse modo, autores como Harvey (2001), Castells (2003), Tori (2010), Martins dos Anjos (2012), entre outros têm mostrado as mudanças que a educação vem sofrendo a partir do uso das TIC's no processo de ensino aprendizagem. Essas mudanças ocorreram devido aquelas terem cntribuido para criação de uma nova cultura e um novo modelo de sociedade (Kenski, 2001) que busca a tecnologia, principalmente a internet como um dos meios para adiquir conhecimento e de interação.

No entanto, mesmo aquela fazendo parte do cotidiano de várias sociedades, não significa que é a solução para todos os problemas da humanidade (Nascimento \& Sainz, 2017). Assim, nem todos os grupos sociais a usam da mesma forma ou ainda que todos os povos possuem acesso a ela. Além disso, em salas de aulas virtuais assim como outros locais de aprendizagem existe uma variedade de sujeitos, os quais podem apresentar diferentes dificuldades de adaptabilidade e 
aprendizado (Nascimento et al., 2011). Portanto, o professor precisa pensar bastante em que contexto e conteúdo desse ser colocado nesse espaço.

Assim, as TIC's passaram a ser foco de estudos e pesquisas em diferentes áreas de conhecimento, porém as pesquisas sobre essa temática em sua maioria tratam do uso da tecnologia e poucas são sobre as práticas pedagógicas usadas nos ambientes virtuais de aprendizagem (Almeida et al., 2007). Vale destacar que, a entrada das tecnologias de informação e comunicação na educação modificou o processo de ensino aprendizagem, já que extrapolou os limites e espaço temporais da escola e modificou os papéis dos(as) docentes e discentes, bem como criou novas possibilidades de interação (Nascimento \& Sainz, 2017). Assim, os ambientes virtuais de aprendizagem só foram possíveis com a entrada das TIC's na educação, pois elas permitiram construir uma nova modalidade de educação, ou seja, a educação à distância (Coll \& Monereo, 2010).

Como desdobramento dos debates da formação, apresentaremos algumas atividades realizadas durante a formação, entre as quais destaca-se a sala de aula virtual, bem como as possibilidades e dificuldades durante a realização das aulas virtuais.

\section{Metodologia}

\section{1 Área de estudo}

O município de Breves está localizado no Marajó, no Estado do Pará, Brasil (Figura 1). Este é um dos maiores arquipélagos flúvio-marítimo do mundo, seu território é formado por várias ilhas com rios, igarapés e furos, além de rica sociobiodiversidade (Costa, 2016).

O município de Breves apresenta alguns destaques em relação a outros municípios Marajoaras, entre eles estão alguns serviços de saúde e educação, o que faz muitas pessoas de outros locais se deslocarem até a sede daquele município para ter acesso a serviços de saúde e educação (Guedes, 2020).

Figura 1. Localização do município de Breves, Marajó, Pará, Brasil.

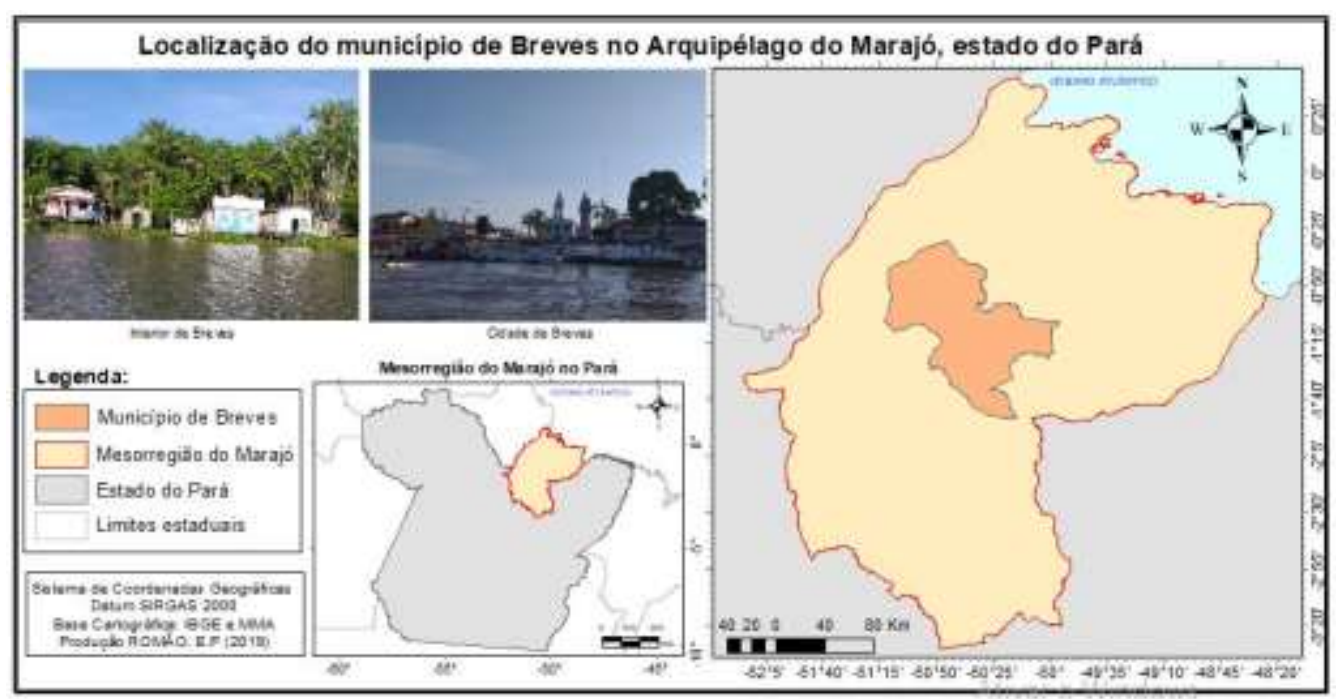

Fonte: Éssia Romão (2020).

\subsection{Projeto educando pelos rios marajoaras}

Projeto "Educando pelos rios marajoaras: ações e estratégias para promoção da equidade racial durante a pandemia (COVID 19)" foi financiado pela Pró-reitora de Extensão (PROEX) do Instituto Federal de Educação, Ciência e Tecnologia do 
Pará (IFPA), sob o edital número 04/2020. O projeto foi executado por docentes e discentes do IFPA-Campus Breves. O público-alvo foram docentes, técnicos e coordenação pedagógica de duas escolas municipais e uma escola estadual todas localizadas no município de Breves, as escolas envolvidas foram: Escola Municipal de Ensino Fundamental Professor Estevão Gomes, Escola Municipal de Ensino Fundamental Bom Jesus e Escola Estadual de Ensino Médio Gerson Peres, respectivamente.

\subsection{Coleta e análise dos dados}

O percurso metodológico foi a pesquisa bibliográfica sobre a temática étinico-racial e a mediação educacional através das TICS's e, a pesquisa-ação. Esta última, contribuiu no desenvolvimento das atividades e para análise dos resultados. A observação empírica é importante para compreensão de algumas realidades e dificuldades. Dessa forma, pode contribuir para buscar ações de combate ao racismo nas escolas.

Assim, uma das primeiras atividades do projeto citado foi analisar as principais problemáticas enfrentadas pelos(as) docentes das escolas de Educação Básica que participaram do projeto, para desenvolver atividades educacionais numa perspectiva antirracista.

A formação ocorreu durante as duas últimas semanas do mês de março de 2021, de modo totalmente online e contou com atividades síncronas, através da plataforma Google Meet, e atividades assíncronas na plataforma Google Sala de Aula. Estas atividades, foram divididas em 5 aulas, das quais duas foram teóricas, uma minicurso e duas foram atividades práticas por meio de oficinas, todas sobre a temática racial numa proposta de educação antirracista e de valorização da diversidade racial e étnica do país.

Além disso, durante as aulas, foram disponibilizados formulários de frequência com algumas perguntas sobre o curso e sobre as atividades que os(as) participantes desenvolviam em sala de aula virtual. Os dados gerados pelos questionários aplicados através do Google Forms foram analisados pelos(as) bolsistas do projeto.

\section{Resultados e Discussão}

\subsection{A formação}

Os espaços escolares, sejam presenciais ou online, possuem como características a ampliação do convívio social, que deixa de ser prioritariamente a família e estende-se aos(às) colegas e profissionais da educação com os quais convivem. Esse contato proporciona aos(as) alunos(as), uma gama de relações sociais com seus pares e com profissionais da educação, com diferentes subjetividades, etnias, gêneros, identidades e sexualidades, relações essas que influenciam na formação da identidade e autoimagem do(a) educando(a).

Assim, as práticas pedagógicas devem promover a valorização das identidades negras, indígenas, entre outras, bem como a autoestima dos(as) discentes. Além disso, deve se comprometer com a promoção e respeito do indivíduo e suas relações coletivas. Vale destacar que, os professores(as) que não foram preparados(as) para lidar com as diferenças geralmente acabam padronizando o comportamento dos(as) alunos(as). Mas é difícil encontrar docentes que estejam preparados(as) para lidar com os desafios que a discriminação racial impõe em sala de aula "[...], já que muitos não tiveram em sua formação debates relacionados a temática racial, e isso é um reflexo do mito de democracia racial existente no Brasil que nega o racismo e assim, não prioriza uma educação antirracista (Munanga, 2005).

Foi nesse contexto que a formação do projeto intitulada "Teorias, conceitos e práticas pedagógicas para uma educação antirracista no Marajó” foi pensada, a qual visava proporcionar reflexões, debates e práticas pedagógicas inovadoras aos docentes da Educação Básica do município de Breves para discutir a temática racial em sala de aula. A formação ocorreu em 
duas semanas com cinco aulas ao vivo pela plataforma Google Meet (Figura 2 e 3), e com aulas e materiais disponibilizados na sala de aula virtual da plataforma google sala de aula e contou com diversos professores(as) de diferentes idades, bem como outros(as) profissionais da educação. Além de profissionais de diferentes áreas do conhecimento como, por exemplo, de serviço social, entre outras.

Figura 2. Aula na plataforma Google Meet.

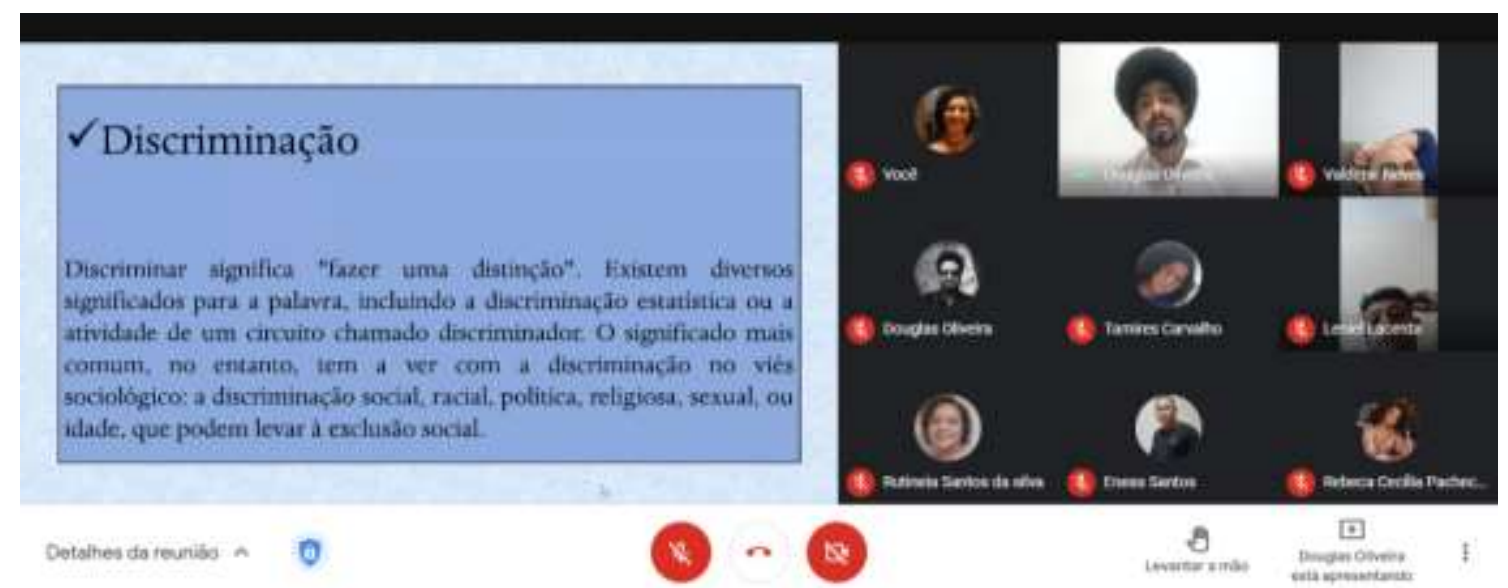

Fonte: Ana Célia Guedes (2021).

Figura 3. Aula na plataforma Google Meet.

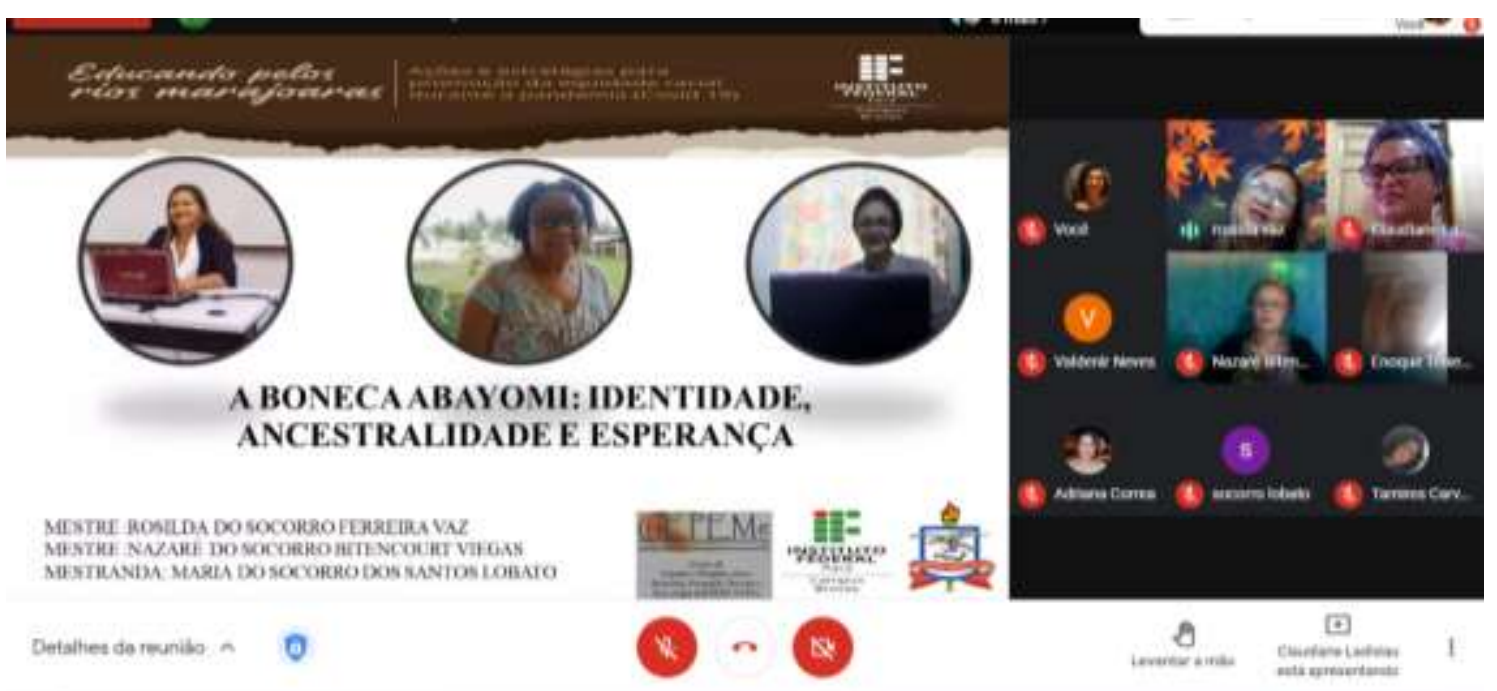

Fonte: Ana Célia Guedes (2021).

A formação contou com aulas teóricas sobre conceitos como racismo, injuria racial e a importância de uma educação antirracista, bem com minicurso sobre práticas pedagógicas inovadoras e oficinas com práticas pedagógicas sobre a temática racial. As discussões foram interdisciplinares, pois havia profissionais de diferentes áreas, assim buscou-se atender professoras(as) da área das humanidades, linguagens, ciências naturais, e matemática, visto que todas as áreas devem procurar metodologias educativas, conceitos, fundamentos e princípios que visem uma educação antirracista. Vale destacar que somente como uma leitura crítica do racismo estrutural e dos lugares e não lugares que os(as) negros(as) ocupam na sociedade brasileira pode ocorrer a implementação de uma educação antirracista e o debate acerca das relações étnico-raciais, principalmente no que tange à cultura africana e afro-brasileira, como forma de respeito às diversas pluralidades sociais, raciais, culturais e de gênero existentes em nossa sociedade. 


\subsection{A sala de aula virtual}

As salas de aulas virtuais também chamadas de Ambientes Virtuais de Aprendizagem são locais de interações e aprendizagem (Nascimento \& Sainz, 2017). Para Mill e Fidalgo (2006), os espaços e lugares são compreendidos a partir de sua função, assim a sala de aula é entendida como um espaço de ensino-aprendizagem por ser planejada e desenvolvida com o objetivo pedagógico. A sala de aula é uma construção histórica (Dussel \& Caruso, 2003), pois foi construída e reconstruída socialmente ao longo dos séculos.

De acordo com Silva (2010), nesse local de aprendizagem existe uma gestão e construção interligada de informação, comunicação e aprendizagem que ocorre de forma Online. A aprendizagem virtual pode ocorrer de forma síncrona e assíncrona (Coll \& Monereo, 2010) dependendo do(a) professor(a) ou tutor(a) da turma, ou mesmo do contexto e realidade $\operatorname{dos}($ as) alunos(as).

Nessa perspectiva, o(a) professor(a) deve oferecer apoio, gerenciamento e controle tanto dos conteúdos quanto do acesso e navegação dos(a) discentes (Nascimento \& Sainz, 2017), o que não quer dizer que aquele(a) é o detentor(a) do conhecimento, ao contrário deve ser o(a) mediador(a) da aprendizagem, assim como ocorre nas salas de aula presenciais, visto que nesse ambiente deve ser desenvolvida a metodologia por meio da Práxis Pedagógica, visando uma educação crítica e libertadora a partir da pedagogia Freireana, a qual afirma que não há espaço para arrogância daqueles que se intitulam detentores(as) do conhecimento, pois o(a) educador(a) não é o(a) que apenas educa, mas também o(a) que é educado(a), em diálogo com o(a) discente que, ao ser educado(a), também educa (Freire, 1987).

Nas salas de aulas virtuais são colocadas diversas ferramentas computacionais que permitem autonomia, interatividade e colaboração dos(as) discentes (Nascimento \& Sainz, 2017), todas essas ferramentas são suportes importantes ao processo de ensino aprendizagem tanto no ensino presencial quanto a distância. Desse modo, os ambientes virtuais de aprendizagem devem ser pensados, planejados e projetados para facilitar o acesso a materiais de aprendizagem e a comunicação entre alunos(as) e professores(as) e entre os(as) próprios(as) estudantes (Coll \& Monero, 2010), uma vez que nesse espaço é possível desenvolver uma aprendizagem coletiva e individual.

Vale destacar que, o uso de salas de aulas virtuais tem aumentado consideravelmente nos últimos anos, principalmente após a Pandemia causada pela COVID-19, pois mesmo os(as) professores(as) das instituições de ensino que não desenvolviam aulas no formato virtual se viram obrigados(as) a aprender a lidar com novas ferramentas tecnológicas e com novas formas de ensinar e aprender. Para tanto, tiveram que fazer diversos cursos como, por exemplo, sobre metodologias ativas, manuseio de ferramentas e plataformas de aprendizagens, dentre outros.

Foi nesse contexto que a formação "Teorias, conceitos e práticas para uma educação antirracista foi desenvolvida". Assim, foi criada uma sala de aula virtual na plataforma Google Sala de Aula, na qual foram postados vários materiais relacionados às temáticas da formação, tais como: artigos científicos, documentários, links de materiais em vídeo, fórum, link das aulas gravadas e atividades.

Vários(as) participantes da formação, sobretudo os que não conseguiam acompanhar as aulas síncronas, acessaram a sala de aula virtual assistiram as aulas gravadas, leram os artigos, responderam as atividades e interagiram no fórum, este último foi muito importante, pois se tornou o espaço de interação da turma no qual foi possível debater sobre a temática da formação e refletir sobre o racismo estrutural e metodologias para combatê-lo, como podemos observar no trecho abaixo retirado de um dos fóruns.

Uma metodologia muito interessante citada pelo professor Raime foi a utilização da biografia de mulheres negras que são símbolos das lutas sociais no Brasil, mas que são pouco conhecidas. Ele mostrou o trabalho que ele elaborou sobre 
estas mulheres de forma a tornar registro oficial a ser trabalhado em sala de aula. Nesta metodologia temos duas lutas: a dos negros é a das mulheres (Registro da participação de Adriana Sanches no fórum da sala virtual, 28/03/2021).

O registro acima mostra que é possível ter a participação e interação entre os(as) estudantes e professores(as) em sala de aulas virtuais, além de interação entre os(as) próprios estudantes de uma determinada formação ou disciplina. Portanto, os fóruns devem ser utilizados, visto que são importantes para criar espaços para ambientar o participante à ferramenta de navegação na sala de aula virtual, ao mesmo tempo que pode criar laços afetivos de solidariedade, respeito, entre outros entre os participantes (Tavares-Silva et al., 2005).

Para tanto, é preciso que ocorra um planejamento da disciplina, dos conteúdos, dos materiais e das perguntas ou das afirmativas que serão colocadas no fórum de modo a impulsionar o debate e a participação da turma, pois a participação dos(as) alunos(as) é de suma importância no processo de ensino aprendizagem. Nesse sentido, a tecnologia, nesse caso usada para se obter a sala de aula virtual, contribuiu para a realização da formação em prol de uma educação antirracista.

\subsection{As aulas virtuais: possibilidades e dificuldades enfrentadas durante a formação}

A formação ocorreu no formato totalmente online, desse modo, as aulas aconteceram de forma síncrona e assíncrona. Para as aulas assíncronas optou-se pela plataforma Google Sala de Aula (GSA) e para as aulas síncronas ocorreram através de webconferência pela plataforma Google Meet, tal escolha se deu devido essas plataformas serem mais leves, acessíveis e a maioria dos docentes sinalizaram ter conhecimento sobre elas. Pesquisadores como Angeli et al. (2003) \& Pesce et al. (2011), entre outro têm desenvolvido pesquisas e mostrado que a webconferência é uma ferramenta que pode fomentar o ensinoaprendizagem, pois ela favorece à ação mediadora contribuinte dos processos de aprendizagem e promove à formação de comunidades virtuais de aprendizagem.

Para as aulas assíncronas foram disponibilizados vários materiais como textos em PDF, links das aulas tanto dos(as) professores(as) convidados(as) quanto outras de canais do YouTube, links de documentários, fórum e atividades para que os(as) participantes pudessem ter acesso a vários materiais sobre a temática racial. Além de poderem interagir com seus(suas) colegas de curso, professores(as) e bolsistas que auxiliaram na formação. Os materiais foram postados e os(as) participantes tiveram um mês para acessá-los e responder as atividades e participar dos fóruns, porém nem todos(as) acessaram os materiais.

As aulas síncronas foram distribuídas em cinco momentos, cada um com duração de duas (2) horas e foram ministradas por professores(as) coordenadores(as) e por colabores(as) do projeto, bem como por professores(as) convidados(as). Em cada aula foi debatido uma temática diferente, tais como educação antirracista, conceito de raça, racismo e injuria racial, além de minicursos e oficinas de práticas pedagógicas inovadoras sobre a temática racial.

As primeiras aulas síncronas contaram com um número significativo de participantes e a maioria se mostrou bastante interessado(a) na temática, assim, participaram quando solicitados(as) pelo(a) professor(a) que ministrou a aula ou até mesmo espontaneamente. No entanto, nas últimas aulas síncronas, se observou que diminuiu consideravelmente o acesso dos(as) participantes, entre os motivos destacados por eles(as) para não terem participado, destaca-se os problemas de acesso à internet no município de Breves.

Esse problema de acesso à internet foi uma das maiores dificuldades para o desenvolvimento da formação, outro motivo observado foi a dificuldades em lidar com a tecnologia, pois as inscrições para participar da formação foram realizadas pela plataforma Even 3, e o link do Google Meet, onde foram realizadas as aulas síncronas era logado no Even 3, logo os(as) participantes deveriam entrar com seu login e senha na referida plataforma e acessar o link do meet correspondente ao dia, horário e tema da aula, tais informações foram disponibilizadas por e-mail, WhatsApp e estavam também no Even 3. 
No entanto, poucos(as) participantes conseguiam realizar esse processo, desse modo, os(as) organizadores(as) da formação tiveram que criar um grupo de WhatsApp para melhor orientá-los(as), lá também foram disponibilizados um tutorial em PDF e os links de acesso às aulas síncronas para aqueles(as) que não conseguiam acessar pelo Even3. Observou-se ainda que, a maioria dos(as) docentes que participaram da formação acessaram as aulas por celular, ao serem indagados(as) por que não usavam um computador ou notebook, muitos responderam que não possuíam ou que seus(as) filhos(as) estavam usando para ter acesso às aulas remotas. O que nos leva a refletir que ao cesso a esses materiais, indispensáveis ao trabalho docente, não é democratizado, principalmente nesse período de pandemia da COVID-19, pois os preços de computadores e notebook dobraram, assim como os preços dos produtos da cesta básica, porém os salários dos(as) docentes foi congelado, o que impossibilita a compra desses equipamentos para trabalhar ou participar com boa qualidade de uma formação.

\section{Considerações Finais}

Diante do acirramento das tensões sociais, do agravamento das desigualdades socioeconômicas e do aumento do racismo no Brasil, causados pela pandemia da COVID-19, considera-se urgente a criação de espaços que possibilitem debates e discussões sobre questões raciais, as quais afetam uma parcela significativa da população brasileira e, sobretudo a marajoara, que tem em sua formação grande contribuição do povo negro e indígena. Estes novos espaços, sendo virtuais, trouxeram novas possibilidades de estratégias através das TIC's.

Assim, foi possível desenvolver uma formação multidisciplinar, considerando que em todas as áreas deve-se praticar uma educação antirracista que valorize a história, a cultura e a ancestralidade dos povos negros e indígenas e seu legado na formação socioculturais de nosso país, mas que, devido ao racismo estrutural, sofreram e ainda sofrem apagamentos socioculturais através da invisibilidade e negação de seu legado.

Compreendemos que a formação "Teorias, conceitos e práticas pedagógicas para uma educação antirracista no Marajó" oportunizada pelo Projeto Educandos pelos rios Marajoaras veio em um momento necessário para o contexto da Educação Básica do município de Breves e do Marajó, como possibilidade de lançar novos olhares sobre a temática para muito além das ações pontuais do dia da consciência negra.

Inversamente a uma data específica percebe-se que, atualmente cada vez mais, vêm se desenvolvendo ações e estudos sobre a temática afrodescendente brasileira, trazendo à tona importantes discussões que ampliam reflexões, tanto em âmbito escolar quanto no cotidiano sociocultural de qualquer indivíduo que seja alcançado.

Nesse sentido, acredita-se que a formação ofertada por este projeto estimulou positivamente futuros debates entre os(as) professores(as) marajoaras, por meio dos quais estudantes e comunidade local serão provocados a novas reflexões que corroborem para a valorização da ancestralidade africana em seu meio, não apenas no presente, mas para o futuro de uma geração que valorize sua identidade e que tenha mais autônoma.

\section{Agradecimentos}

Ao Instituto Federal de Educação, Ciência e Tecnologia do Pará (IFPA), Campus Breves.

Aos docentes, pela colaboração na pesquisa.

À Pró-Reitoria de Extensão (PROEX) do Instituto Federal de Educação, Ciência e Tecnologia do Pará (IFPA), pelo financiamento na pesquisa (Edital $\left.n^{\circ} 04 / 2020\right)$. 
Research, Society and Development, v. 10, n. 11, e41101117673, 2021

(CC BY 4.0) | ISSN 2525-3409 | DOI: http://dx.doi.org/10.33448/rsd-v10i11.17673

\section{Referências}

Almeida, M. E. B., Vecchio, R. D., Cerny, R. Z., \& Krüger, S. E. (2007). Estratégias para ensinar e aprender em ambientes virtuais. CINTED-UFRGS Novas Tecnologias na Educação, 5(2).

Angeli, C., Valanides, N., \& Bonk, C.J. (2003). Communication in a Web-based conferencing system: The quality of computer-mediated interactions. British Journal of EducationalTechnology, 34(1), 31-43.

Castells, M. (2003). A galáxia da Internet: reflexões sobre a Internet, os negócios e a sociedade. Jorge Zahar.

Coll, C., \& Monereo, C. (2010). Psicologia da Educação Virtual. Aprender e ensinar com as tecnologias da informação e da comunicação. Artmed, 365.

Costa, E. M. (2016). Dos indígenas, os artefatos: a história dos povos indígenas do Arquipélago do Marajó, PA. Revista de Estudos Linguísticos, Literários, Culturais e da Contemporaneidade. 18(3), 144-154.

Dussel, I., \& Caruso, M. (2003). Sala de aula? genealogia? definições para iniciar o percurso. In: Dussel, I.; Caruso, M. A invenção da sala de aula: uma genealogia das formas de ensinar. Moderna, 29-46.

Freire, P. (1987). Pedagogia do Oprimido. (10a ed.) Paz e Terra.

Gonçalves, L. C., Ramirez, M. A., \& Santos, D. (2016). Extensão rural e conexões. FEPMVZ, p. 164.

Guedes, A. C. B., Vieira, R. M., \& Castro, N. M. S. (2020). Educação para as relações étnico-raciais: ações e estratégias de promoção da equidade racial em Breves/Marajó. In: Coelho, W. de N. B., et al. (orgs). Práticas antirracistas no Pará: Educação para as Relações Étnico-Raciais - NEAB's e NEABI's paraenses em ação. Curitiba: CRV, 2020.

Harvey, D. (2001). Condição pós-moderna. (10a ed.), Loyola.

Jantke, R. V. R., \& Caro, S. M. P. (2013). A extensão e o exercício da cidadania. In: Luiz Síveres. (Org.). A extensão universitária como princípio de aprendizagem. Liber Livro, 1, 97-108.

Kenski, V. M. (2001). Múltiplas linguagens na escola. In: CANDAU, Vera Maria. Linguagens, espaços e tempos no ensinar e aprender. Rio de Janeiro: DP\&A, 123-139.

Martins-Anjos, A. (2012). Tecnologias da informação e da comunicação, aprendizado eletrônico e ambientes virtuais de aprendizagem. In: MACIEL, Cristiano (Org.). Ambientes virtuais de aprendizagem. EduFMT.

Mill, D., \& Fidalgo, F. (2007). Espaço, tempo e tecnologia no trabalho pedagógico: redimensionamento na Idade Mídia. Revista Brasileira de Estudos Pedagógicos, 88(220), 411-697.

Nascimento, C. O., Moreira, M. I. G., Cancela, M. T., \& Sainz, R. L. (2011). O Desenho Organizacional da EaD: a experiência no âmbito do NETTAD. Anais... In: VIII Congresso Brasileiro de Ensino Superior a Distância. Ouro Preto.

Nascimento, C. O, \& Sainz, R. L. (2017). Aprendizagem em ambientes virtuais: tecendo reflexões sobre espaço relacional-emocional. Revista Thema, 14(4), $149-158$.

Pesce, L., Hessel, A., \& Bruno, A. R. (2011). Educação e tecnologias: a contribuição da webconferência à aprendizagem em rede. In: Barros, D. M. V. et al. (Org.). Educação e Tecnologias: reflexão, inovação e práticas. Educação e Tecnologias: reflexão, inovação e práticas. Lisboa: Universidade Aberta de Portugal, 1, 1-21.

Portes, M. R., Ananias, S. P., \& Teixeira, H. A. (2011). Ensino do Empreendedorismo e Extensão Universitária: uma política pedagógica articulada. Anais... In: VIII - Congresso Virtual Brasileiro de Administração, 2011.

Schlemmer, E. (2005). Metodologias para educação a distância no contexto da formação de comunidades virtuais de aprendizagem. In: Barbosa, R. M. (Org.). Ambientes virtuais de aprendizagem. Artmed, p. 29-49.

Silva, F. N. L. (2017). Piscicultura marajoara”: formação extensionista, diagnóstico e intervenções em comunidades por educandos do Instituto Federal de Educação, Ciência e Tecnologia do Pará campus Breves. Especialização em Docência para o Ensino Tecnológico, Científico e Profissional, 131 f. Instituto Federal de Educação, Ciência e Tecnologia do Pará-IFPA, Campus Breves.

Silva, M. (2010). Educar na Cibercultura: Desafios à formação de professores para docência em cursos online. Revista Digital de Tecnologias Cognitivas, PUC-SP, 2010, $\mathrm{n}^{\circ}$ 3. https://www4.pucsp.br/pos/tidd/teccogs/artigos/2010/edicao_3/3-educar_na_ciberculturadesafios_formacao_de_professores_para _docencia_em_cursos_online-marco_silva.pdf>

Tavares-Silva, T., Coelho, S. Z., \& Valente, J. A. (2005). A Educação baseada no paradigma da produção em massa, de servidores do estado, via cursos online, potencializando a capacidade de pensar e criar do aprendiz. In: Ricardo, E. J. (Org.) Educação corporativa e educação a distância. Qualitymark.

Tori, R. (2010). Educação sem distância: as tecnologias interativas na redução de distâncias em ensino e aprendizagem. São Paulo: Editora Senac. 